\title{
A study of effectiveness of injection Depot medroxyprogesterone in postpartum women
}

\section{Priya G. Dhameliya*, Parul T. Shah, Shlok V. Patel, Dhanvi J. Deliwala, Kinjal Kotahri}

Department of Obstetrics and Gynaecology, NHL, MMC, Ahmedabad, Gujarat, India

Received: 08 June 2021

Revised: 08 July 2021

Accepted: 09 July 2021

\section{*Correspondence:}

Dr. Priya G. Dhameliya,

E-mail: priya94dhameliya@gmail.com

Copyright: ( ) the author(s), publisher and licensee Medip Academy. This is an open-access article distributed under the terms of the Creative Commons Attribution Non-Commercial License, which permits unrestricted non-commercial use, distribution, and reproduction in any medium, provided the original work is properly cited.

\begin{abstract}
Background: Depot medroxyprogesterone (DMPA) injection $150 \mathrm{mg}$ intramuscular was used in postpartum women for contraception in this study, once every 3 months. The aim of the study acceptance and compliance of DMPA, observe side effects related to usage of DMPA and establish its effectiveness as a postpartum contraception method.

Methods: This is a prospective study carried out at Obstetrics and Gynaecology department over a period of 9 months and follow up was done. Only patients of full term normal delivery and Lower segment caesarean section (LSCS) were included. They were counselled properly and after their willingness for enrolment they were included in study after taken consent.

Results: Out of 50 cases selected maximum patients, $48 \%$ were in the age group of 26 to $30,38 \%$ were from lower socioeconomic class. Amenorrhoea and irregular spotting were found in $68 \%$ and $42 \%$ respectively. There was no case of failure of this contraceptive method in this study.

Conclusions: DMPA is an effective and safe method of contraception in lactating period. Proper counselling will increase acceptance of DMPA. Awareness in patients regarding its benefits as compared to other contraceptive methods.
\end{abstract}

Keywords: Injection DMPA, Postpartum contraception, Fertility

\section{INTRODUCTION}

Population explosion is one of the major problems of developing countries like India. Modern Contraceptive prevalence rate worldwide is $55 \%$ for married women in $2020 .^{1}$ Government tries to reduce birth by various measures but unawareness and ignorance towards contraception remains higher and results in failure of these measures. Moreover, contraception in the postpartum period is a major challenge. Popular methods offered are barrier methods, progesterone pills, PPIUCD, sterilization, Depot medroxyprogesterone acetate (DMPA). Inj Depot medroxyprogesterone has been found to provide effective, long acting and reversible contraception. ${ }^{2}$ Its 12 -week dosing interval results in patient convenience, avoids need for daily compliance or use at time of intercourse. It is to be given deep intramuscular so not much training of staff is required. One injection at every three months and less side effects makes compliance better in temporary motivated postpartum women specially in low resource settings.

In nonpregnant patients Ideal time to initiate DMPA is within 5 days of onset of menses; it rules out her pregnancy and prevents ovulation during first month of use. Injectable DMPA use as a contraceptive in the immediate postpartum period was found to be a safe and effective alternate method with no deleterious effect on mother's milk and infant growth. ${ }^{3}$ 
Injection DMPA has a typical use failure rate of 0.3 per 100 women. $^{4}$ Major side effects with DMPA include menstrual disturbance, weight gain, mood changes etc. injection DMPA does not have any permanent effect on fertility. It has been shown that after discontinuance of DMPA, the mean time for the return of ovulation (210 days) is only slightly less than the mean time for the return of fertility (260 days). ${ }^{5}$

Here we aim to study acceptance and effect of DMPA in the postpartum period.

\section{METHODS}

\section{Study type}

The type of study was prospective, interventional, longitudinal and a single centered study.

\section{Study site}

The study was conducted at the Obstetrics and Gynaecology Department SVP hospital and SCL hospital, Ahmedabad.

\section{Study duration}

The study was conducted for a total duration of 9 month from October 2019 to June 2020.

\section{Study method}

Prior approval to conduct the study was taken from all Head of the units and then patients were enrolled in the study. Study group received DMPA $150 \mathrm{mg}$ intramuscularly during the lactation period. According to inclusion criteria, they were given DMPA every 3 month. Microsoft excel is used to analyse the data.

\section{Inclusion criteria}

Postpartum full term delivered patients ,with age between 21 to 35 years, desiring for long term ,non coitus dependent contraception, willing for regular follow up and ready to participate for study with giving consent and apparently healthy with no associated medical conditions can be included in the study .

\section{Exclusion criteria}

Postpartum delivered patients but not willing to participate and give consent for enrolment, high risk patients and patients above 35 years of age were excluded.

All women willing for contraception were given options and explained well about benefits and side effects of each contraceptive methods. Women opting for DMPA were chosen for this study. After proper counselling and informed written consent 50 women were enrolled in the study. All women underwent through general physical examination. DMPA $150 \mathrm{mg}$ IM given deep intramuscular in upper lateral gluteal region using 24 -gauge needle. The schedule consisted of injection within 6 weeks of postpartum ${ }^{6}$ All women were asked to maintain a diary to remember the date of their next injection. All women were regularly followed after the first injection for side effects, failure, patient satisfaction and willingness of continuation.

\section{RESULTS}

Table 1 shows that out of the 50 patients included in this study, 35 were delivered vaginally and 15 by caesarean section. mode of delivery does not affect the use of contraception.

Table 1: Mode of delivery.

\begin{tabular}{|l|l|}
\hline Mode of delivery & No. of patients \\
\hline ND & 35 \\
\hline LSCS & 15 \\
\hline
\end{tabular}

Table 2: Patients characteristics.

\begin{tabular}{|llll|}
\hline Age/parity & Primipara & $2^{\text {nd }}$ para & $\begin{array}{l}3^{\text {rd }} \text { and } \\
\text { more }\end{array}$ \\
\hline $\mathbf{2 1 - 2 5}$ & 04 & 06 & 01 \\
\hline $\mathbf{2 6 - 3 0}$ & 07 & 14 & 03 \\
\hline $\mathbf{3 1 - 3 5}$ & 03 & 03 & 09 \\
\hline
\end{tabular}

Table 3: Total injections.

\begin{tabular}{|lll|}
\hline No. of injections & $\begin{array}{l}\text { No. of } \\
\text { patients }\end{array}$ & $\%$ \\
\hline $\mathbf{1}$ & 09 & 18 \\
\hline $\mathbf{2}$ & 24 & 48 \\
\hline $\mathbf{3}$ & 15 & 30 \\
\hline $\mathbf{3}$ & 02 & 04 \\
\hline
\end{tabular}

Table 4: Side effects.

\begin{tabular}{|lll|}
\hline Side effects & $\begin{array}{l}\text { No. of } \\
\text { patients }\end{array}$ & $\%$ \\
\hline Amenorrhoea & 34 & 68 \\
\hline Irregular bleeding & 21 & 42 \\
\hline $\begin{array}{l}\text { Weight gain and mood } \\
\text { changes }\end{array}$ & 4 & 8 \\
\hline $\begin{array}{l}\text { Headache and } \\
\text { abdominal pain }\end{array}$ & 5 & 10 \\
\hline Miscellaneous* $^{*}$ & 2 & 4 \\
\hline
\end{tabular}

"backache, dyspareunia, erythema nodosum.

Our study included apparently healthy women in the age group of 21 to 35 . Majority of the patients who took inj DMPA were 2nd para patients and between in the age group of 26-30 years. 
second para patients were willing to participate as the majority of them had completed their family and were able to understand the benefits of DMPA in comparison to others methods.

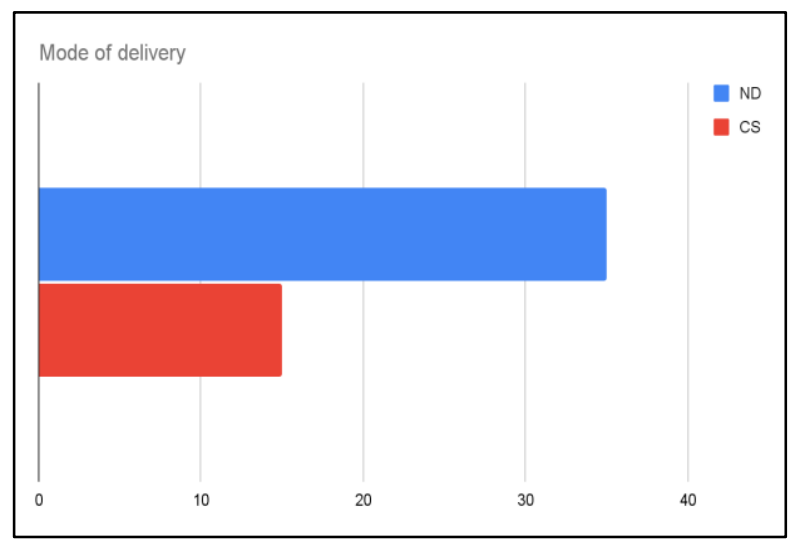

Figure 1: Side effects.

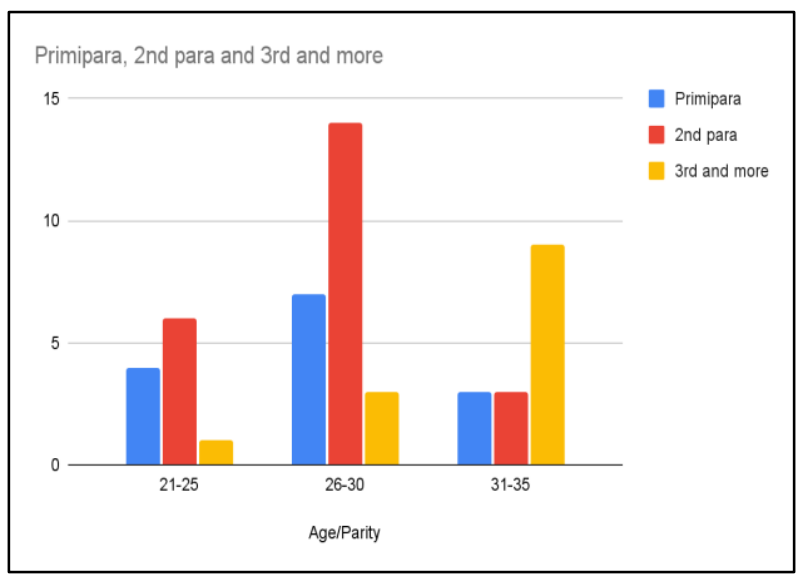

Figure 2: Age and parity.

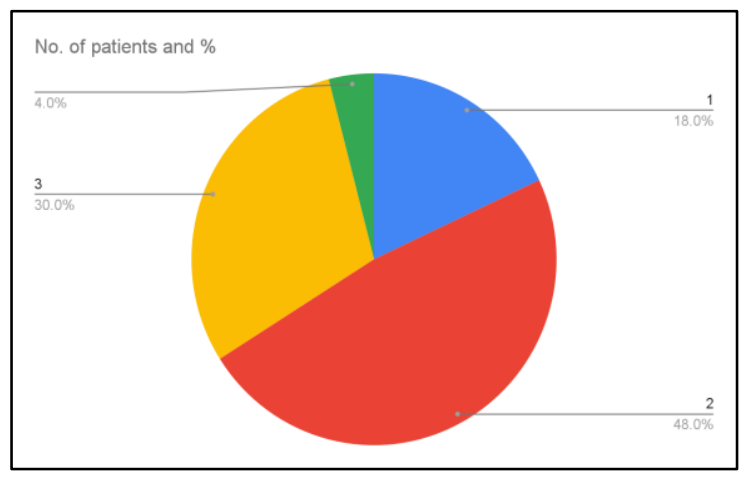

Figure 3: Number of injections.

Majority of our patients were from lower middle class $(25.5 \%), 19 \%$ were from lower socio-economic class while $5.5 \%$ from upper middle class.

$48 \%$ of patients took 2 injections, $30 \%$ took 3 injections and all patients were followed up for any complaints or side effects.

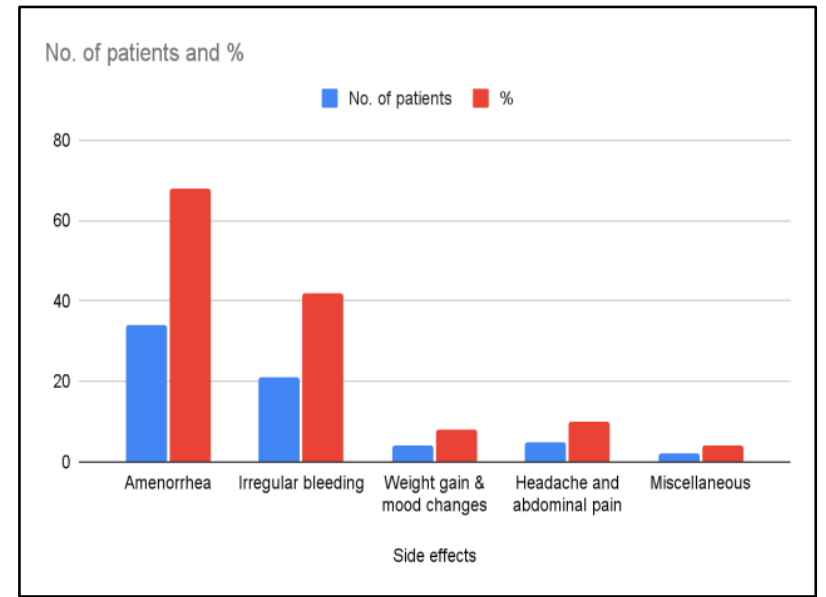

Figure 4: Side effects.

Out of 50 about $68 \%$ reported amenorrhoea, and $42 \%$ had an irregular bleeding. $8 \%$ had mood changes Few had other side effects like headache, abdominal pain and weight gain etc. None of the females conceived during the study period. One or more than one side effects were found in many patients.

All the subjects were followed for up to 9 months. At the end of study $70 \%$ of women were happy with DMPA as contraception and opted to continue it while others switched to alternate contraceptive methods.

\section{DISCUSSION}

Birth control methods have been used since ancient times, but effective and safe methods only became available in 20th century. ${ }^{7}$

Planning provision and use of birth control is called family planning.

Depot medroxyprogesterone acetate is a highly effective, safe and long-term method of contraception. DMPA, when given every 12 weeks, is a highly effective, non daily hormonal contraceptive with a very low failure rate comparable to modern cu IUCDs and lower than many other methods. The effectiveness of long-acting reversible contraception is superior to that of contraceptive pills, patch, or ring and is not altered in adolescents and young women. ${ }^{8}$

Major complication leading to discontinuation of its use is amenorrhoea (68\%) and related menstrual irregularities (42\%). Irregular bleeding is scanty and rarely heavy thus fear of anaemia is less, besides amenorrhoea is beneficial in women with anaemia and others like menorrhagia and dysmenorrhoea. Weight gain associated with DMPA use was only marginal and could not be attributed to DMPA alone. DMPA has many other non-contraceptive benefits such as prevention of endometrial cancer, ectopic pregnancy, dysmenorrhea and in management of endometriosis. Use of DMPA has no permanent effect on 
fertility. Unlike the barrier method it is coitus independent and hassles of daily intake like combined pills were not there.

Most important issue regarding use of DMPA is that of patient information. A proper antenatal counselling of women about injection DMPA will increase the acceptance and efficacy.

Awareness of patients regarding use of DMPA with its beneficial effect during the postpartum period is very much needed. Though it has limitations in the form of side effects like menstrual problems, delayed return of fertility may be regardless of the duration of its use. ${ }^{9}$ Its compliance and acceptability are not that easily seen in many groups of patients. In the emergency group of patients, it was not a readily accepted method due to lack of counselling. The sample size of our study was limited due to COVID era.

\section{CONCLUSION}

DMPA contains medroxyprogesterone acetate $(150 \mathrm{mg})$ works by preventing ovulation and thickening of mucus in cervix and hence preventing sperms to enter uterus. Its long acting effectiveness and convenience has made it the most suitable method for contraception. Patients are advised to continue during lactation. as small amount gets into milk but does not alter quantity of milk. Injectable DMPA in postpartum period is safe and effective method with less side effects hence its use as a first line method to all postpartum women who wish a long-term reversible method of contraception should be widely done. Menstrual side effects limiting use of DMPA can overcome with proper counselling and education.
Funding: No funding sources

Conflict of interest: None declared

Ethical approval: The study was approved by the Institutional Ethics Committee

\section{REFERENCES}

1. WHO- family planning/contraception method. https://www.who.int/news-room/fact-sheets/deta il/family-planning-contraception. Accessed on 10th May, 2021.

2. Isabel M, Rodriguez MI. An evidence-based approach to postpartum use of depot medroxyprogesterone acetate in breastfeeding women, controversies in reproductive health. 2009;80(1):4-6.

3. Singhal S, Sarda N, Goel S. Impact of injectable progestogen contraception in early puerperium in lactation and infant health. JDCR.

4. Depot medroxyprogesterone acetane(DMPA). The oncofertility consortium. https://oncofertility.m su.edu/resources/depot-medroxyprogesteroneacetane-dmpa. Accessed on $10^{\text {th }}$ May, 2021.

5. Fotherby K. J Obstet Gynaecol (Lahore). 1986;2:S110-5.

6. Kaunitz, Andrew M. Injectable long-acting contraceptives. Clin Obst Gyncol. 2001;44(1):73-91.

7. Hanson SJ, Burke, Anne E. Fertility control: contraception, sterilization, and abortion. In: The Johns Hopkins Manual of Gynecology and Obstetrics. Kurt H. 4th ed. Wolters Kluwer Health, Philadelphia, USA: Lippincott Williams \& Wilkins. 2010;382-95.

8. Funded by the Susan Thompson. N Engl J Med. 2012;366:1998-2007.

9. Andrew M, Kaunitz. Return to fertility, Clinical obstetrics and gynecology. 2001;44(1):73-5.

10. Contraception/injectable progestin contraceptives. In: Williams Obstetrics. Chapter 38 2th edition.

Cite this article as: Dhameliya PG, Shah PT, Patel SV, Deliwal DJ, Kotahri K. A study of effectiveness of injection Depot medroxyprogesterone in postpartum women. Int J Reprod Contracept Obstet Gynecol 2021;10:3128-31. 